\title{
A tri-mode high light-load efficiency BUCK converter for mobile phone application
}

\author{
Cui Qing ${ }^{\text {a) }}$ and Lin Fujiang \\ Department of Electronic Science and University of Science and Technology of \\ China, Hefei 230027, China \\ a)cuiqingblue10@126.com
}

\begin{abstract}
This paper proposes a wide output range and tri-mode BUCK circuit which utilizes PWM mode, PFM mode and PSM mode at heavy, light and very light loads respectively. By shutting down the majority of the internal modules, employing minimum loop control and reducing the quiescent current, the design could lower the static power consumption. The work, therefore, could increase efficiency at very light load. The proposed BUCK is fabricated using SMIC $0.18 \mu \mathrm{m}$ process. Test results show that when the input is $4 \mathrm{~V}$ and the output is $1.8 \mathrm{~V}$, the efficiency of the proposed BUCK is $90 \%$ and $85 \%$ at $300 \mathrm{~mA}$ and $5 \mathrm{~mA}$ load current respectively.
\end{abstract}

Keywords: BUCK, PSM, wide output range

Classification: Integrated circuits

\section{References}

[1] J. S. Chang, et al.: "Fast Output Voltage-Regulated PWM Buck Converter With an Adaptive Ramp Amplitude Control,” IEEE Trans. Circuits Syst. II, Exp. Briefs 60 (2013) 712 (DOI: 10.1109/TCSII.2013.2277986).

[2] Z. Zhang, et al.: "Adaptive Current Source Drivers for Efficiency Optimization of High-Frequency Synchronous Buck Converters," IEEE Trans. Power Electron. 27 (2012) 2462 (DOI: 10.1109/TPEL.2011.2175453).

[3] P. J. Liu, et al.: “A High-Efficiency CMOS DC-DC Converter With 9- $\mu$ s Transient Recovery Time,” IEEE Trans. Circuits Syst. I, Reg. Papers 59 (2012) 575 (DOI: 10.1109/TCSI.2011.2167259).

[4] M. D. Mulligan, et al.: "A constant-frequency method for improving light-load efficiency in synchronous buck converters," IEEE Power Electron. Lett. 3 (2005) 24 (DOI: 10.1109/LPEL.2005.845177).

[5] W. Yan, et al:: “A Noise-Shaped Buck DC-DC Converter With Improved Light-Load Efficiency and Fast Transient Response," IEEE Trans. Power Electron. 26 (2011) 3908 (DOI: 10.1109/TPEL.2011.2136361).

[6] C. Pi, et al.: "DCM, FSM, dead time and width controllers for a high frequency high efficiency buck DC-DC converter over a wide load range," J. Semicond. 31 (2010) 0850031 (DOI: 10.1088/1674-4926/31/8/085003).

[7] B. Yuan, et al.: "Load current-sensing circuit integrated in high-frequency PWM/PFM hybrid DC-DC buck converter," Electron. Lett. 50 (2014) 1310 (DOI: 10.1049/el.2013.4206).

[8] S. Sugahara, et al.: "90\% High Efficiency and 100-W/cm bm3 High Power Density Integrated DC - DC Converter for Cellular Phones," IEEE Trans. Power Electron. 28 (2013) 1994 (DOI: 10.1109/TPEL.2012.2197762). 
[9] J.-C. Tsai, et al.: "Dual Modulation Technique for High Efficiency in HighSwitching Buck Converters Over a Wide Load Range," IEEE Trans. Circuits Syst. I, Reg. Papers 58 (2011) 1671 (DOI: 10.1109/TCSI.2011.2142970).

[10] R. W. Erickson and D. Maksimovic: Fundamentals of Power Electronics (Kluwer, New York, 2011) 1st ed. 48.

[11] Texas Instruments: TPS62290 datasheet (2016) http://www.ti.com.

[12] Linear Technology: LTC1875 datasheet (2016) http://www.linear.com.

\section{Introduction}

With the continuous development of consumer electronics, especially for portable devices such as mobile phones, the power consumption of the mobile chips is continuously increased at the same time. BUCK DCDC converter technology has been increasingly used in this field to reduce power consumption. At the same time, considering multiple complex applications of the phone operation system, not only the efficiency under high current load, but also the light load efficiency when the system is in sleep status is needed to be taken into account, especially when the latter truly reflects the phone's standby time. Since the load of BUCK is usually a digital chip for the mobile application, the output ripple is required to be very low, even less than $25 \mathrm{mV}$. As a result, output ripple is a more sensitive parameter for digital chip than efficiency. Efficiency will only effect the power dissipation, but output ripple will result in both the abnormal of logic and uncontrollable of power dissipation.

BUCK modulator usually uses PWM [1, 2] (Pulse Width Modulation) control under CCM (continuous conduction mode) state with large load current. When the circuit switches to light load current, the system is in DCM (discontinuous conduction mode) state, the efficiency of the circuit is affected by many factors such as dead time and is more sensitive than CCM. If PWM control is still used in this situation, the efficiency will drop dramatically. In order to improve light load efficiency, by optimizing the driver control of power output device, some of designs reduce the switching losses $[3,4]$. Some researches use digital control to optimize light load efficiency, such as the sigma-delta modulation proposed in [5]. The light load efficiency can also be improved by optimizing the dead time of power switch and adjustment size of power output device [6]. However, the most popular technology used to improve efficiency is switching the circuit into PFM (Pulse Frequency Modulation) mode when the circuit is working under DCM state by using heavy and light load dual-mode [7, 8]. Comparing with PWM mode, PFM shows higher efficiency under light load due to its frequency modulation characteristics. However, the quiescent current in PFM mode is still relatively high because the operational amplifier loop which is used to control the system consumes considerable power. The best efficiency of reference designs $[3,6,9]$ in PFM is lower than $80 \%$. Thus, the demand of high efficiency could not be met if the load is extremely low (lower than $5 \mathrm{~mA}$, for example).

In this paper, a BUCK converter containing PWM, PFM and PSM (Pulse skip 
Units) application. The circuit diagram is showed in Fig. 1. The internal register of PMU is controlled by DBB (Digital Baseband) through the I2C interface. Register control circuit switches the loop between the two states. The first state is PWM and PFM automatic switching control. When applications for mobile phone systems, under large load, ripple optimization could be reached through PWM mode. Under light load, the circuit is working in PFM mode and the efficiency is still at a high level. It should be noted that due to no mobile phone software control is operated between light and heavy load switch, DBB cannot send a signal to control BUCK to change the operating loop state. Therefore, it needs auto transition technology between PWM and PFM modes. In addition, before mobile phone enters into sleep mode, phone software system will make the digital chip which is load of BUCK into low power state or shut down. At this time, the load current of BUCK becomes very low or even just the leakage current of the digital chip. As a result, the DDB will switch the BUCK into second state by setting the corresponding register through $\mathrm{I}^{2} \mathrm{C}$ interface, and the BUCK is in low power mode. While under this very light load, a new PSM mode is proposed. In this mode, only a low-power comparator is used to control the entire work loop circuit, and the number of the circuit in the loop is decreased to the minimum one. The new design can minimize the static power consumption and effectively enhance the efficiency under very light load. The efficiency is $85 \%$ under $5 \mathrm{~mA}$ loads and hence can realize high efficiency over full load range. The output voltage range covers 0.5 to $3.4 \mathrm{~V}$, and $800 \mathrm{~mA}$ loads can be driven. Fabricated using SMIC $0.18 \mu \mathrm{m}$ process, efficiency higher than $85 \%$ can be reached for load current from 5 to $800 \mathrm{~mA}$. When output is $1.8 \mathrm{~V}$, loads is $10 \mathrm{~mA}$, and output capacitor is $10 \mu \mathrm{F}$, the output ripple is only $10 \mathrm{mV}$, which is more lower than similar works.

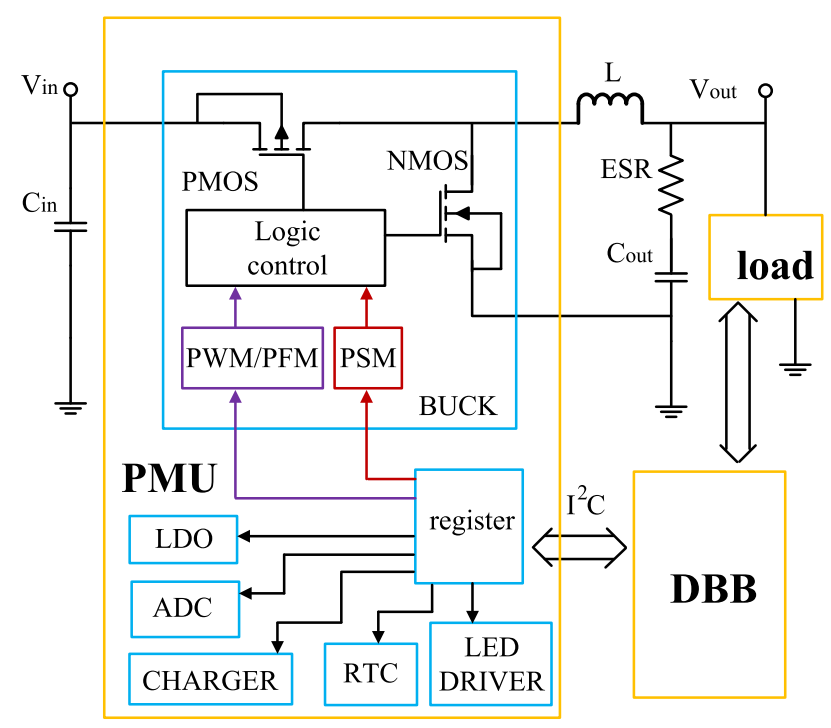

Fig. 1. BUCK circuit architecture for mobile phone application 


\section{Tri-mode control technology}

\subsection{PWM and PFM modes}

Fig. 2 shows the circuit architecture of PWM and PFM. VFB is feedback voltage divided by the output voltage through R1 and R2. VFB and reference voltage REF1 are respectively the negative and positive inputs of EA, the output voltage of EA is $\mathrm{V}_{\mathrm{C}}, \mathrm{V}_{\mathrm{R}}$ is added by the ramp-on-a-step current-sensing voltage $\mathrm{V}_{\mathrm{SE}}$ and slope compensation voltage $\mathrm{V}_{\mathrm{SL}}$. The circuit detects the output $\mathrm{V}_{\text {out }}$ and regulates $\mathrm{V}_{\mathrm{C}}$. In PWM mode, at every clock pulse, logic control block is reset, causing PMOS transistor to turn on. The PWM comparator compares the $V_{R}$ to $V_{C}$. Hence when the peak of $V_{R}$ equals $V_{C}$, the PWM output goes positive, set logic control block, PMOS power transistor turns off and NMOS power transistor turns on. The duration of the on state of PMOS transistor equals $\mathrm{D} * \mathrm{~T}$, where $\mathrm{D}$ is the duty cycle set by the logic control, expressed as a ratio of the switch on time to the time of one complete switching cycle, T. When VFB is higher than REF1, $V_{C}$ become lower, the duty cycle is decreased and the output $\mathrm{V}_{\text {out }}$ will decrease. When VFB is lower than REF1, $\mathrm{V}_{\mathrm{C}}$ becomes higher, and the duty cycle is increased which makes the output $\mathrm{V}_{\text {out }}$ increased.

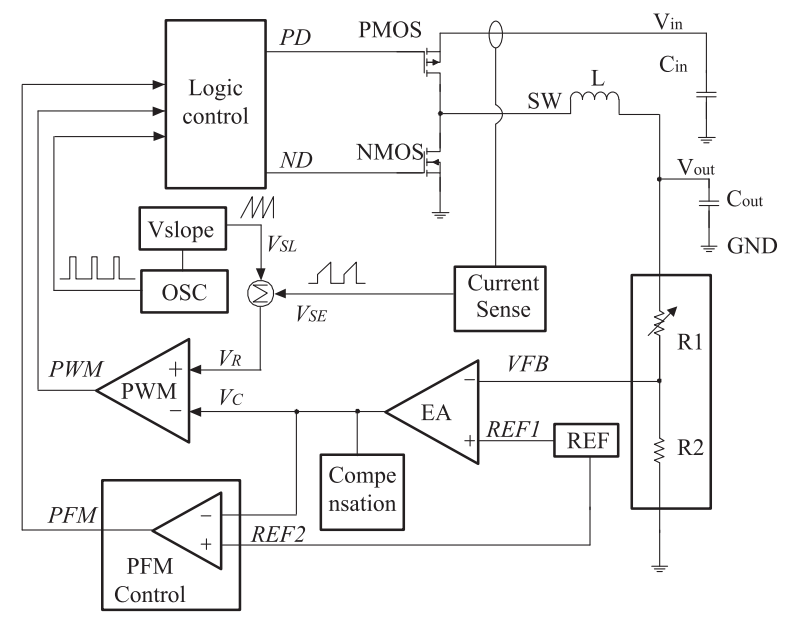

Fig. 2. PWM and PFM modes

When the loads become lower, the output $\mathrm{V}_{\text {out }}$ gradually increases. $\mathrm{V}_{\mathrm{C}}$ decreases to be lower than REF2, the output of PFM comparator control transits from low to high. This will trigger the state of PFM and consequently turn off PMOS and NMOS power transistors. $\mathrm{V}_{\text {out }}$ will decrease during off state of PMOS and NMOS power transistors. When PFM signal is low, PMOS and NMOS power transistors continue to work. The circuit essentially regulates the low peak of $\mathrm{V}_{\mathrm{C}}$ and sets the high peak when $V_{C}$ increases to hysteretic high threshold. Fig. 3 shows the main waveforms of PWM and PFM modes. Under PWM mode, PMOS and NMOS power transistors turn on and off once during each switch cycle. But for PFM mode, the PMOS and NMOS power transistors will be in on or off states only if the PFM signal is low. In addition, the PFM signal is useful to determin when it is necessary to transit into the PFM mode, the circuit is auto transition between PWM and PFM modes, according to the relationship between $\mathrm{V}_{\mathrm{C}}$ and REF2. 


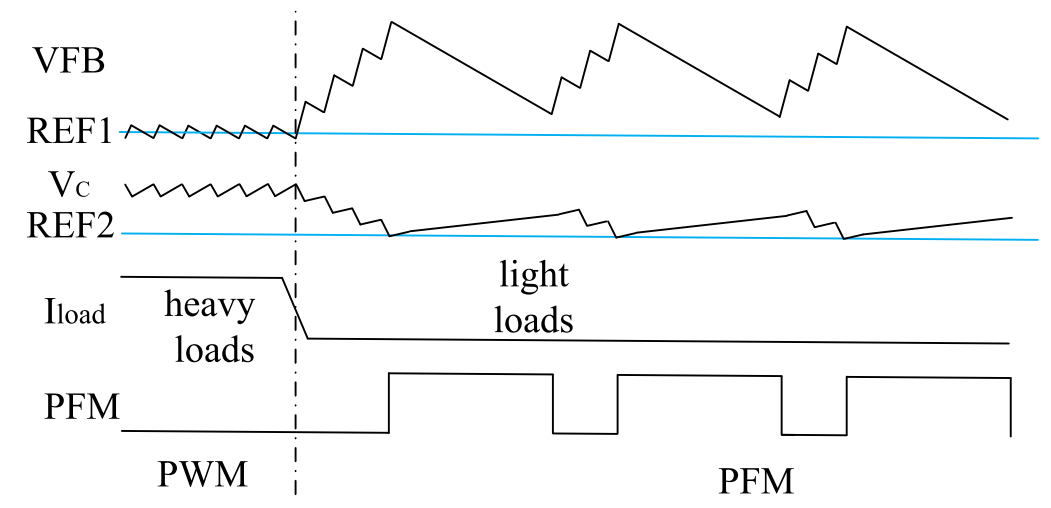

Fig. 3. Main waveforms of PWM and PFM modes

\subsection{PSM mode}

Fig. 4 shows circuit architecture and main waveforms of PSM mode under DCM mode. When mobile phone is in sleep mode controlled by software of phone, the internal register of low power mode is wrote by DDB though $\mathrm{I}^{2} \mathrm{C}$ interface. The circuit is under PSM mode, only one reference and one PSM comparator are used. For each waveform, a switching cycle consists of three parts. During t1, VFB voltage equals the low threshold REF3 set by the internal control logic, PMOS power transistor is on, NMOS power transistor is off and the input power supply storages energy into inductance and provides current to load. When VFB reaches to the high threshold REF4 at the start point of t2, PMOS power transistor switches off, NMOS power transistor switches on and the inductance starts to freewheel. After the inductance finished discharging, during t3, both PMOS and NMOS power transistors switch off, the voltage of SW terminal equals DC voltage of $\mathrm{V}_{\text {out }}$ and the output capacitor provides load current.

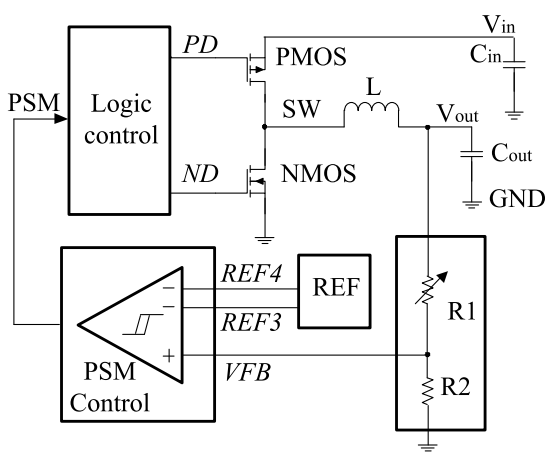

(a)

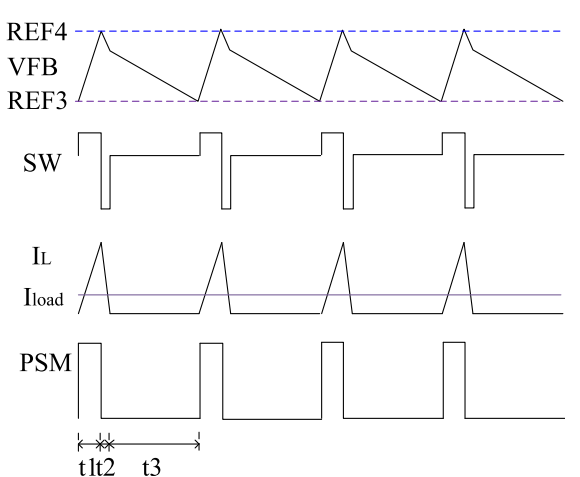

(b)

Fig. 4. (a) Circuit architecture (b) Main waveforms of DCM mode

Through analyzing power consumption of the BUCK circuit, an optimization solution to enhance efficiency is given. The power consumption of the BUCK circuit consists of three parts, DC loss $\left(\mathrm{P}_{\mathrm{dc}}\right), \mathrm{AC}$ losses $\left(\mathrm{P}_{\mathrm{ac}}\right)$, and circuit static loss $\left(\mathrm{P}_{\mathrm{q}}\right)$. Among them, $\mathrm{P}_{\mathrm{dc}}$ mainly refers to the power loss caused by the on-resistance of the PMOS and NMOS power transistors. $\mathrm{P}_{\mathrm{ac}}$ losses mainly due to the charge and discharge of gate capacitances $C_{n}$ and $C_{p}$ when the PMOS and NMOS power transistors switch between on and off states. While circuit static loss means analog 
control circuit static power consumption, such as the current consumption of the internal reference circuits.

According to reference [10], the power loss is given. The DC loss of NMOS and PMOS power transistors is given by:

$$
\begin{gathered}
P_{d c(P M O S)}=\frac{\left(V_{\text {in }}-V_{\text {out }}\right)^{2} t_{1}{ }^{3}}{3 L^{2} T} R_{d s o n(P M O S)} \\
P_{d c(N M O S)}=\frac{V_{\text {out }} t_{2}{ }^{3}}{3 L^{2} T} R_{d s o n(N M O S)}
\end{gathered}
$$

Where $\mathrm{R}_{\mathrm{dson}(\mathrm{PMOS})}$ and $\mathrm{R}_{\mathrm{dson}(\mathrm{NMOS})}$ is on-resistance of PMOS and NMOS power transistors. The AC loss of PMOS power transistor $\mathrm{P}_{\mathrm{ac}}$ (PMOS), and AC loss of NMOS power transistor $\mathrm{P}_{\mathrm{ac}(\mathrm{NMOS})}$, are calculated out as formula (3) and (4) respectively:

$$
\begin{aligned}
& P_{a c(P M O S)}=\frac{C_{p} V_{i n}{ }^{2}}{T} \\
& P_{a c(N M O S)}=\frac{C_{n} V_{i n}{ }^{2}}{T}
\end{aligned}
$$

Besides, the circuit static loss is given in formula (5)

$$
P_{q}=I_{q} V_{\text {in }}
$$

When the circuit work at very light loads condition, for instance, lower than $10 \mathrm{~mA}$, the DC loss $\mathrm{P}_{\mathrm{dc}}$ and static loss $\mathrm{P}_{\mathrm{q}}$ are main sources of power consumption. Increasing width to length ratio of NMOS and PMOS power transistors can reduce $\mathrm{R}_{\mathrm{dson}}$ to decrease $\mathrm{P}_{\mathrm{dc}}$. However, this method will result in several problems including higher $\mathrm{P}_{\mathrm{ac}}$ due to the larger $\mathrm{C}_{\mathrm{p}}$ and $\mathrm{C}_{\mathrm{n}}$, and higher output ripple under DCM mode resulted from lower $\mathrm{R}_{\mathrm{dson}}$. But large output ripple is not acceptable in mobile phone application. In this paper, PSM modulation mode is used to reduce circuit static power and DC loss, while $\mathrm{P}_{\mathrm{ac}}$ and output ripple are not increased, providing high very light load efficiency. Referring to Fig. 4, since the ripple voltage of VFB, which is derived from the output voltage via a feedback resistor divider, is usually determined by the difference between REF3 and REF4, the reasonable configuration of the voltage REF3 and REF4 can be used to obtain smaller output ripple.

The difference of control loop between PFM and PSM mode is below. For the PSM structure under light load, the modulating frequency is decreased to reduce $\mathrm{P}_{\mathrm{dc}}$ and $\mathrm{P}_{\mathrm{ac}}$, and the majority blocks of the loop of PFM control are also closed, including core sampling circuit current (Current Sense), the main operation amplifier (EA), overcurrent protection unit (OCP), slope compensation $\left(\mathrm{V}_{\text {slope }}\right)$, pulse width modulation comparator (PWM). At this time, the PSM control circuit is simplified and it only contains reference circuit, PSM control circuit, feedback resistors R1, and R2.

\section{Simulation and measurement results}

This paper proposes a synchronous buck converter based on SMIC $0.18 \mu \mathrm{m}$ CMOS technology. The convertor has a wide output range and high efficiency under light load and low output ripple. The output capacitor is $4.7 \mu \mathrm{F}$. The simulations results 


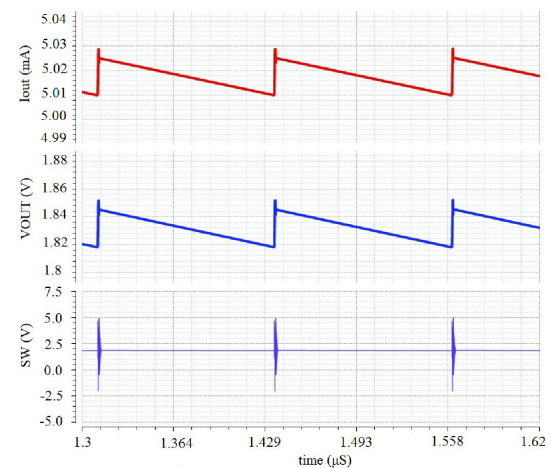

Fig. 5. Simulation of output voltage of PSM mode

are shown in Fig. 5 demonstrate that the output ripple is $23 \mathrm{mV}$ with $5 \mathrm{~mA}$ load current under PSM mode.

The chip photo and package are shown in Fig. 6.

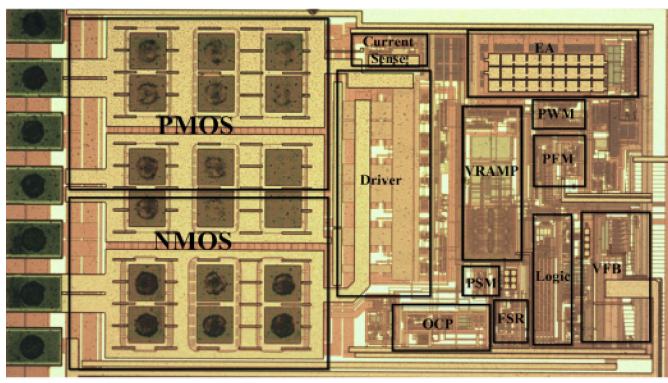

(a)

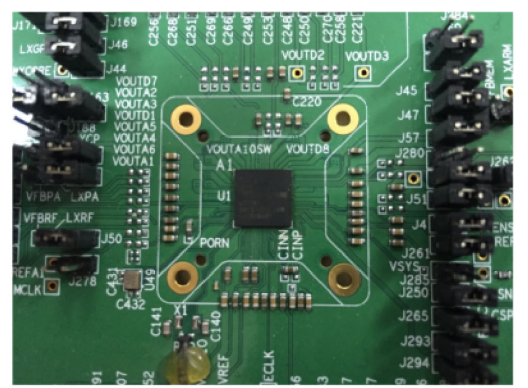

(b)

Fig. 6. (a) Chip micrograph (b) Chip package

Fig. 7 shows the waveforms of output voltage and SW side under different mode. The input voltage is $4 \mathrm{~V}$, the output voltage is $1.8 \mathrm{~V}$, the output capacitor is $10 \mu \mathrm{F}$ and the output inductor is $2.2 \mu \mathrm{H}$. It can be seen that the circuit can operate properly in the all three operation modes. For PWM mode, one switching cycle of NMOS and PMOS power transistor is performed for each clock period. For PFM mode, the main loop is shielded once PFM is triggered and restarts after voltage begin to decrease. And for the new PSM mode, both NMOS power transistor and PMOS power transistor are only controlled by PSM comparator.

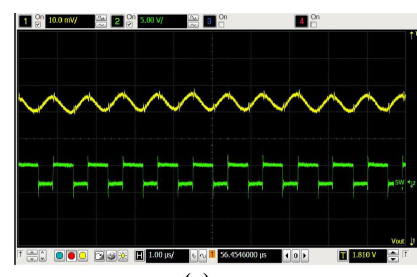

(a)

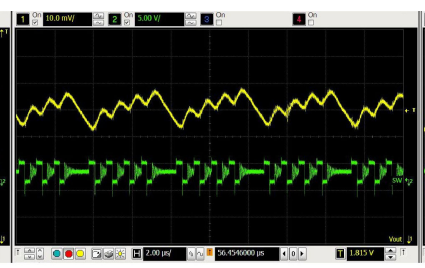

(b)

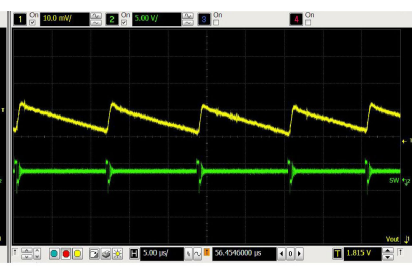

(c)

Fig. 7. Test waveforms (a) PWM mode (b) PFM mode (c) PSM mode

Fig. 8 shows the test efficiency curves of circuit with load from 0.5 to $800 \mathrm{~mA}$. Comparing with the traditional dual-modes, the light-load efficiency of the new PWM, PFM, and PSM tri-modes circuit shows a great improvement. For $1.8 \mathrm{~V}$ output, $0.5 \mathrm{~mA}$ loads, $20 \%$ efficiency improvement is achieved. While under $5 \mathrm{~mA}$ 


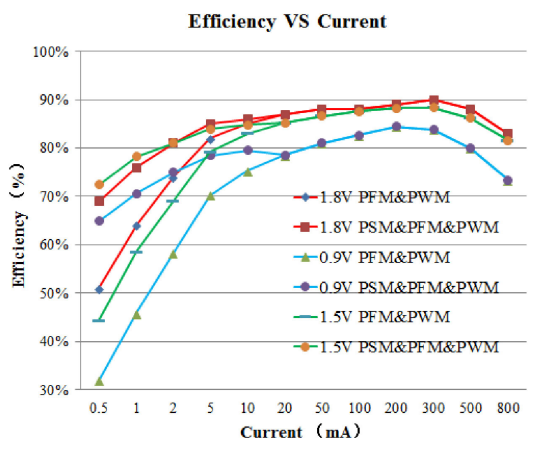

Fig. 8. Efficiency curve

load, $10 \%$ efficiency improvement is achieved. Above $85 \%$ efficiency can be reached for load current from 5 to $800 \mathrm{~mA}$. As a result, the efficiency of the proposed BUCK keeps at a relative high level over the full load range.

Since this work is part of a mobile phone PMU which uses BGA package and double base board, the power route of PCB cannot be the shortest path which is easily realized in single-chip application. As a result, the large parasitic resistors of the power route will make a lot of DC loss, which hence makes the efficiency of the proposed BUCK cannot reach the level of single-chip. Table I shows the perform-

Table I. Performance list and comparison with other designs

\begin{tabular}{|c|c|c|c|c|c|c|}
\hline Parameter & TCSI [9] & TCSI [3] & JOS [6] & TI [11] & LTC [12] & This work \\
\hline $\begin{array}{l}\text { Technology } \\
(\mu \mathrm{m})\end{array}$ & 0.25 & 0.35 & 0.35 & $\begin{array}{c}\text { Not } \\
\text { mention }\end{array}$ & $\begin{array}{c}\text { Not } \\
\text { mention }\end{array}$ & 0.18 \\
\hline Package & $\begin{array}{c}\text { Not } \\
\text { mentioned }\end{array}$ & $\begin{array}{c}\text { Not } \\
\text { mentioned }\end{array}$ & $\begin{array}{c}\text { Not } \\
\text { mentioned }\end{array}$ & WSON & SSOP & BGA \\
\hline $\begin{array}{c}\text { Input } \\
\text { range }(\mathrm{V})\end{array}$ & $3-4.5$ & $2.6-3.6$ & 3.6 & $2.3-6$ & $2.65-6$ & $3.2-4.2$ \\
\hline $\begin{array}{c}\text { Output } \\
\text { range }(\mathrm{V})\end{array}$ & 1.8 & $0.6-2.1$ & 1.8 & 1.8 & $0.8-\mathrm{V}_{\text {in }}$ & $0.5-3.4$ \\
\hline $\begin{array}{c}\text { Switching } \\
\text { frequency } \\
(\mathrm{MHz})\end{array}$ & 5 & 1 & 10 & 2.2 & 0.55 & 1.5 \\
\hline Mode & $\begin{array}{c}\text { PWM\& } \\
\text { HFM }\end{array}$ & PWM & $\begin{array}{l}\text { PWM\& } \\
\text { FSM }\end{array}$ & $\begin{array}{c}\text { PWM\& } \\
\text { PFM }\end{array}$ & $\begin{array}{l}\text { PWM\& } \\
\text { BURST }\end{array}$ & PWM\&PFM\&PSM \\
\hline $\begin{array}{c}\text { Load } \\
\text { range }(\mathrm{mA})\end{array}$ & 600 & 500 & 600 & 1000 & 1500 & 800 \\
\hline $\mathrm{L}(\mu \mathrm{H})$ & 1 & 22 & 0.47 & 2.2 & 6.8 & 2.2 \\
\hline $\mathrm{C}(\mu \mathrm{F})$ & 4.7 & 22 & 4.7 & 10 & 47 & 4.7 \\
\hline Area $\left(\mathrm{mm}^{2}\right)$ & 1.38 & 3.04 & 1.4 & $\begin{array}{c}\text { Not } \\
\text { mentioned }\end{array}$ & $\begin{array}{c}\text { Not } \\
\text { mentioned }\end{array}$ & 0.5 \\
\hline $\begin{array}{c}\text { Efficiency } \\
(\%)\end{array}$ & $\begin{array}{c}1.8 \mathrm{~V} 70 \% \\
\text { (a) } 10 \mathrm{~mA}\end{array}$ & $\begin{array}{c}1.8 \mathrm{~V}: 70 \% \\
@ 10 \mathrm{~mA}\end{array}$ & $\begin{array}{c}1.8 \mathrm{~V}: 80 \% \\
\text { (a) } 10 \mathrm{~mA}\end{array}$ & $\begin{array}{l}1.8 \mathrm{~V}: 91 \% \\
\text { @, } 5 \mathrm{~mA}\end{array}$ & $\begin{array}{l}1.8 \mathrm{~V}: 87 \% \\
\text { (a) } 5 \mathrm{~mA}\end{array}$ & $\begin{array}{c}1.8 \mathrm{~V}: 86 \% @ 10 \mathrm{~mA} \\
1.8 \mathrm{~V}: 85 \% @ 5 \mathrm{~mA}\end{array}$ \\
\hline $\begin{array}{l}\mathrm{V}_{\text {out }} \text { Ripple } \\
\quad(\mathrm{mV})\end{array}$ & $\begin{array}{c}\text { Not } \\
\text { mentioned }\end{array}$ & $\begin{array}{c}\text { Not } \\
\text { mentioned }\end{array}$ & $\begin{array}{c}\text { Not } \\
\text { mentioned }\end{array}$ & $\begin{array}{c}20 \mathrm{mV}: 1.8 \\
\mathrm{~V} @ 10 \mathrm{~mA} \\
\mathrm{C}_{\text {out }}=10 \mu \mathrm{F}\end{array}$ & $\begin{array}{c}80 \mathrm{mV}: 2.5 \\
\mathrm{~V} @ 50 \mathrm{~mA} \\
\mathrm{C}_{\text {out }}=47 \mu \mathrm{F}\end{array}$ & $\begin{array}{c}10 \mathrm{mV}: 1.8 \mathrm{~V} @ 10 \mathrm{~mA}, \\
\mathrm{C}_{\text {out }}=10 \mu \mathrm{F} \\
20 \mathrm{mV}: 2.5 \mathrm{~V} @ 50 \mathrm{~mA}, \\
\mathrm{C}_{\text {out }}=47 \mu \mathrm{F}\end{array}$ \\
\hline $\begin{array}{c}\text { Off-chip } \\
\text { compensation }\end{array}$ & $\begin{array}{c}\text { Not } \\
\text { mentioned }\end{array}$ & $\begin{array}{c}\text { Not } \\
\text { mentioned }\end{array}$ & $\begin{array}{c}\text { Not } \\
\text { mentioned }\end{array}$ & $\begin{array}{c}\text { One } \\
\text { capacitor }\end{array}$ & $\begin{array}{l}\text { two } \\
\text { capacitor } \\
\& \text { one } \\
\text { resistor }\end{array}$ & No need \\
\hline
\end{tabular}


ance comparison with prior designs. It can be seen that the proposed work achieves a higher efficiency than work proposed in $[3,6,9]$ with $1.8 \mathrm{~V}$ output. Although the efficiency of this work is lower than the products proposed in $[11,12]$, the output ripple of the proposed BUCK, which is more important in mobile phone application, is much smaller than those of products proposed in $[11,12]$.

\section{Conclusions}

In this paper, a tri-modes buck converter is presented for mobile phone application. When the system is working in heavy load condition circuit operates in PWM mode, as the load gradually decreases, the circuit enters PFM mode to improve light load efficiency. As the load further reduce to $10 \mathrm{~mA}$ or less, it utilizes a new PSM structure by simplifying loop control, which will minimize static power system, thereby improving the efficiency of very light load DCM mode. The chip is available in a BGA package and does not need off-chip compensation. When the output is $1.8 \mathrm{~V}$, the efficiency of the proposed BUCK is higher than $85 \%$ from $5 \mathrm{~mA}$ to $800 \mathrm{~mA}$, and the output ripple is lower than $20 \mathrm{mV}$. 